Article

\title{
Efficient Catalytic Upgrading of Levulinic Acid into Alkyl Levulinates by Resin-Supported Acids and Flow Reactors
}

\author{
Valeria Trombettoni, Luca Bianchi, Ana Zupanic, Alessandro Porciello, Maurizio Cuomo, \\ Oriana Piermatti (iD, Assunta Marrocchi * and Luigi Vaccaro * \\ Laboratory of Green Synthetic Organic Chemistry, Dipartimento di Chimica, Biologia e Biotecnologie, \\ Università degli Studi di Perugia, via Elce di Sotto 8, 06132 Perugia, Italy; Valeria_G91@hotmail.it (V.T.); \\ luca.bianchi82@gmail.com (L.B.); anamaria.zupanic@gmail.com (A.Z.); porcidduu@gmail.com (A.P.); \\ cuomo.maurizio27@gmail.com (M.C.); oriana.piermatti@unipg.it (O.P.) \\ * Correspondence: assunta.marrocchi@unipg.it (A.M.); luigi.vaccaro@unipg.it (L.V.); \\ Tel.: +39-075-585-5536 (A.M.); +39-075-585-5541 (L.V.)
}

Academic Editor: Giancarlo Cravotto

Received: 24 July 2017; Accepted: 9 August 2017; Published: 15 August 2017

\begin{abstract}
Biomass-derived levulinic acid (LA) is an excellent substrate to obtain high-value esters that can be used as second-generation biofuels and biofuel additives. The present study focuses on the identification and definition of the key parameters crucial for the development of chemically and environmentally efficient protocols operating in continuous-flow for the preparation of structurally diverse alkyl levulinates via the esterification of LA. We have focused on the use of solid acid catalysts consisting of sulfonated cation exchange resins and considered different aliphatic alcohols to prepare levulinates 3 and 11-17 regioselectively, and in good to high yields (50-92\%). Direct correlations between several reaction parameters and catalyst activity have been investigated and discussed to set proper flow reactors that allow minimal waste production during the workup procedure, enabling Environmental factor (E-factor) values as low as ca. 0.3 , full recoverability and reusability of the catalysts, and the production of levulinates up to ca. $5 \mathrm{gxh}^{-1}$ scale.
\end{abstract}

Keywords: biomass; levulinic acid; biofuel additives; catalyst recyclability; heterogeneous catalysis; green chemistry; flow technology

\section{Introduction}

Levulinic acid (LA) has been recognized by the US Department of Energy as one of the top biomass-derived platform molecules, owing to its exceptional reactivity and to the fact that it can be produced at relatively low cost from lignocellulose waste [1-3].

The catalytic upgrading of such a platform molecule into second-generation biofuels and biofuel additives is currently of great interest [4-6]. Particularly, fuel additives based on LA exhibit characteristics that make them appropriate for replacing current cold flow improvers in diesel. They may also be employed as gasoline and diesel oxygenated additives, which help to achieve appropriate lubricity, flash point stability, and cleaner burning fuels. Finally, such derivatives offer the advantage of possessing lower blending volatility than the commonly used ethanol. For instance, LA can be converted into 2-methyl-tetrahydrofuran, a fuel extender and component of the P-series renewable fuels $[7,8]$.

Furthermore, LA derivative $\gamma$-valerolactone can be hydrogenated to valeric acid and subsequently esterified to yield valerates. Gasoline blended with up to $20 \%$ of ethyl valerate is demonstrated to exhibit enhanced properties, including an increase in octane number and a lowering of the content of 
olefins, aromatics, and sulfur. Longer hydrocarbon chain esters exhibit volatility, polarity, and ignition properties that are suitable for diesel [9-11].

Alkyl esters of LA have significant potential as blend components in diesel formulations [12-16]. Such esters are structurally related to the biodiesel fatty acid esters that are used in some low-sulfur diesel formulations, but they do not have their principal drawbacks, i.e., poor oxidative stability, poor low temperature properties, and a tendency towards gum formation. The addition of alkyl levulinates to biodiesel is therefore expected to address these issues. The most studied is a formulation for low-smoke diesel developed by Biofine and Texaco [17] that uses ethyl levulinate as an oxygenated additive. Additionally, ethyl levulinate has been tested as an additive for transportation fuels to improve emissions of nitrogen oxides in high compression diesel engines [18-20]. Also, technological initiatives are being taken to use ethyl levulinate as a $100 \%$ biodegradable neat fuel in the near future [21]. Notably, levulinates are currently in the focus of multiple R\&D initiatives in the field, due to their straightforward accessibility from levulinic acid.

Besides, levulinic acid esters may find an application as alternative green solvents, polymer plasticizers, and fragrances [22].

Consequently, the development of new routes for the production of levulinates from bio-based platform molecules have attracted ever more attention [22,23].

The direct esterification of LA with alcohols, which is typically acid catalyzed by homogeneous catalysts, (e.g., sulfuric acid, phosphoric acid) still remains the most frequently utilized approach [22]. A variety of robust and industrially more benign heterogeneous acid catalysts have been used since recent times for the esterification of levulinic acid (mostly with ethanol), including supported heteropolyacids [24-26], zeolites [27,28], hybrid catalysts [29-32], carbon-based materials functionalized with sulfonic groups [33-36], sulfated metal oxides [37-39], and silicas [40-42].

In this context, it should be noted that organic polymer-supported acid catalysts and, particularly, polystyrene sulfonic acid resins are among the most important heterogeneous acids in industry and have been widely used in reactions such as esterification, etherification, alkylation of phenols, and hydration of olefins [43-45]. In particular, the development of efficient, highly functional, group-tolerant, controlled, and living polymerization methods has allowed for diverse ranges of structures and the tuning of the density of catalyst sites along polymers, as well as the easy incorporation of the catalytic center into polymer structures [43-45]. Yet, there have been only sporadic attempts at the production of alkyl levulinates by esterification of LA with resin-supported acid catalysts [40-42,46]. The only report to date focusing exclusively on such a topic has been very recently published by M.A. Tejero et al. [47], who demonstrated the potential of a range of acidic ion-exchange resins in promoting the esterification of LA with 1-butanol, selectively obtaining LA conversion into butyl levulinate in the range $64-94 \%$.

The present paper is focused on the development of a sustainable approach to alkyl levulinates from LA by using heterogeneous catalysis, safe media and flow conditions aimed at demonstrating how crucial this approach is to access chemically and environmentally efficient protocols [48-51] Notably, to the best of our knowledge, this is the first report on the preparation of levulinates under these conditions.

To this end, a set of acidic resins with different morphologies has been investigated, i.e., Amberlyst $15^{\circledR}$ (A-15) and polystyrene-supported p-toluensulfonic acid (PS-pTsOH), both available in the market, as well as perfluorosulfonic polymer Aquivion ${ }^{\circledR}$ PFSA in the form of micronized pellets (Aquivion mP98) from Solvay Specialty Polymers S.p.A., which has not yet become commercially available. It is well-known in fact that the morphology of polymer-supported catalysts is a critical parameter from the point of view of their use under flow conditions [52].

Thus, A-15 and PS-pTsOH are nearly spherical beads of sulfonated co-polymers of styrene (S) and divinylbenzene (DVB). More specifically, they are classified as macroporous (macroreticular) resins, i.e., a degree of permanent porosity is induced into the resin beads so that a high amount of the acidic sites, although distributed through the bulk of the resin, may be accessible to non-swelling 
solvents and reactants. Macroreticular resins are macroporous, typically showing a high cross-linking ratio. In this case, swelling does not usually produce a noticeable change of the overall resin volume. The permanent porous structure on the resins facilitates, in principle, the flow through the beads of the solvents/reactants, and, therefore, the accessibility of the catalytic sites. However, a high cross-linking degree may limit the access to the sites embedded in the inner polymer matrix regions, since it precludes proper swelling of those regions. On the other hand, Aquivion mP98 is a co-polymer of tetrafluoroethylene and sulfonylfluoride vinyl ether which, after hydrolysis of the sulfonyl fluoride, yields the strongly acidic terminal $-\mathrm{CF}_{2} \mathrm{CF}_{2} \mathrm{SO}_{3} \mathrm{H}$ groups. It has no porosity in the dry state and, as such, depends on being swollen by the reaction medium, giving rise to a porous structure and therefore enabling the diffusion of reactants through the polymer matrix. From the point of view of flow application, it is important to bear in mind that swelling leads to a variation in the overall non-porous resin volume that can be significant. This needs to be taken into account when configuring the flow reactors to avoid, e.g., overpressures. It should also be noted here that the micronized form of Aquivion PFSA (Aquivion mP98) exhibits an average particle size which is smaller than the commercially available Aquivion pellets P98 counterpart (about 0.7 vs. $2.5 \mathrm{~mm}$ ), and this likely makes it more useful as catalytic material. In fact, due to the smaller dimension of the pellets, the stirring of the reactants and the isolation of the product become easier under conventional batch conditions. Also, this form of Aquivion PFSA is expected to be more useful in view of our final set of a flow procedure [53].

The catalyst screening is therefore carried out in the direction of identifying robust and stable organic polymer-based solid acid catalysts, suitable for flow processes, to contribute to improving significantly the overall efficiency of valuable fuel esters' large scale production. Our results demonstrate that a large panel of levulinates can be regioselectively obtained in high yields and isolated, avoiding the need for chromatography with efficient waste-minimization, as confirmed by representative green metrics calculations. The role of various reaction parameters, including the molar ratio of the reactants, the catalyst amount, the temperature, and time is discussed, along with the catalyst recoverability/reusability issue. It will be seen that flow technique may be successfully exploited to improve the efficiency of the process. In fact, we demonstrate here that the employment of flow conditions may help in enlarging the scale of a batch protocol and, besides this, allow to avoid the breakdown to "fines" of the heterogeneous catalyst under stirring in the batch mode, thereby improving its reusability. Further, since in flow systems the substrate is actually forced into intimate contact with an excess of the catalyst [52], higher conversions were achieved (93-99\%).

\section{Results and Discussion}

Table 1 summarizes key catalysts properties, in terms of particle size, porosity, morphology, and acid density, along with their acronyms.

Table 1. Key properties of the tested catalysts.

\begin{tabular}{|c|c|c|c|c|c|c|}
\hline $\begin{array}{l}\text { Catalyst } \\
\text { Name }\end{array}$ & $\begin{array}{l}\text { Particle Size } \\
(\mathrm{mm})\end{array}$ & $\begin{array}{c}\text { Surface } \\
\text { Area }\left(\mathrm{m}^{2} / \mathrm{g}\right)\end{array}$ & $\begin{array}{l}\text { Pore Volume } \\
\qquad\left(\mathrm{cm}^{3} / \mathrm{g}\right)\end{array}$ & Matrix $^{1}$ & $\begin{array}{c}\text { Swelling } \\
\text { Volume }^{2}(\%)\end{array}$ & $\begin{array}{c}\text { Acid Loading } \\
(\mathrm{mmol} / \mathrm{g})\end{array}$ \\
\hline A-15 & $<0.3^{1}$ & $45^{1}$ & $0.4^{1}$ & $\begin{array}{l}\text { Styrene/DVB } \\
\text { (macroreticular) }\end{array}$ & 10 & 4.7 \\
\hline PS-pTsOH & $0.25-0.59^{1}$ & 3.26 & 0.0036 & $\begin{array}{l}\text { Styrene/DVB } \\
\text { (macroporous) }\end{array}$ & 50 & 2.9 \\
\hline $\begin{array}{l}\text { Aquivion } \\
\text { mP98 }\end{array}$ & $\sim 0.70$ & - & - & $\begin{array}{l}\text { Tetrafluoroethylene/ } \\
\text { sulfonylfluoride vinyl } \\
\text { ether (non-porous) }\end{array}$ & 400 & 1.02 \\
\hline
\end{tabular}

The efficiency of A-15, PS-pTsOH, and Aquivion mP98 in the esterification reaction of levulinic acid (LA, 1) has been tested first by employing 1-pentanol (2) as a reference alcohol substrate (Scheme 1). Taking into account the earlier discussion, the swelling behavior of the three different resins after 
contact with 1-pentanol has been also evaluated. In this regard, the increase in volume produced by swelling for the resins featuring very low to no-porosity in the dry state can reach values of up to $400 \%$ (Table 1 and Figure S1, Supplementary Materials, SM).

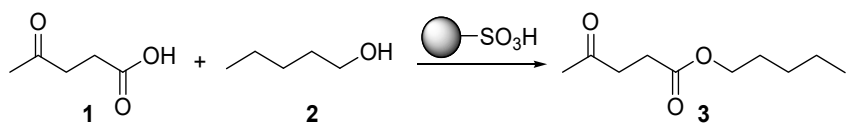

Scheme 1. Synthetic route to pentyl levulinate 3.

The most significant data collected from the batch runs are summarized in Tables 2-4. The blank reaction experiment, in the absence of a catalyst, gave a LA conversion of $\sim 4 \%$ after $24 \mathrm{~h}$ of reaction time (Table S1, entry 1, SM), thereby indicating a negligible extent of the esterification of levulinic acid by auto-catalysis under the tested reaction conditions.

Table 2. Esterification reaction of Levulinic Acid (LA) 1 with 1-pentanol (2) catalyzed by Aquivion mP98.

\begin{tabular}{|c|c|c|c|c|c|}
\hline Entry & Catalyst (mol \%) ${ }^{1}$ & LA/1-Pentanol & $\mathrm{T}\left({ }^{\circ} \mathrm{C}\right)$ & $t(h)$ & $C(\%)^{2}$ \\
\hline 1 & 4.3 & \multirow{9}{*}{$1: 5$} & \multirow{9}{*}{70} & 5 & 45 \\
\hline 2 & 8 & & & & 62 \\
\hline 3 & 10 & & & & 64 \\
\hline 4 & 4.3 & & & 12 & 46 \\
\hline 5 & 8 & & & 12 & $\begin{array}{l}40 \\
66\end{array}$ \\
\hline 6 & 10 & & & & 67 \\
\hline 7 & 4.3 & & & 24 & 53 \\
\hline 8 & 8 & & & & 70 \\
\hline 9 & 10 & & & & 72 \\
\hline 10 & 4.3 & \multirow{9}{*}{$1: 5$} & \multirow{9}{*}{90} & 5 & 50 \\
\hline 11 & 8 & & & & 68 \\
\hline 12 & 10 & & & & 70 \\
\hline 13 & 4.3 & & & 12 & 53 \\
\hline 14 & 8 & & & 12 & 69 \\
\hline 15 & 10 & & & & 73 \\
\hline 16 & 4.3 & & & 24 & 62 \\
\hline 17 & 8 & & & & 73 \\
\hline 18 & 10 & & & & $76(73)^{3}$ \\
\hline 19 & 4.3 & \multirow{9}{*}{$1: 10$} & \multirow{9}{*}{70} & 5 & 47 \\
\hline 20 & 8 & & & & 58 \\
\hline 21 & 10 & & & & 59 \\
\hline 22 & 4.3 & & & 12 & 49 \\
\hline 23 & 8 & & & & 75 \\
\hline 24 & 10 & & & & 77 \\
\hline 25 & 4.3 & & & 24 & 60 \\
\hline 26 & 8 & & & & 82 \\
\hline 27 & 10 & & & & 86 \\
\hline 28 & 4.3 & \multirow{9}{*}{$1: 10$} & \multirow{9}{*}{90} & 5 & 50 \\
\hline 29 & 8 & & & & 63 \\
\hline 30 & 10 & & & & 68 \\
\hline 31 & 4.3 & & & 12 & 58 \\
\hline 32 & 8 & & & & 76 \\
\hline 33 & 10 & & & & 86 \\
\hline 34 & 4.3 & & & 24 & 66 \\
\hline 35 & 8 & & & & 78 \\
\hline 36 & 10 & & & & $92(88)^{3,4}$ \\
\hline
\end{tabular}

${ }^{1}$ Referred to the amount of immobilized $-\mathrm{SO}_{3} \mathrm{H}$ moieties. ${ }^{2}$ LA conversion to pentyl levulinate 3 , determined by ${ }^{1} \mathrm{H}-\mathrm{NMR}$ analysis, using 4-bromoanisole as internal standard; the remaining material was the unreacted mixture of $\mathbf{1}$ and $2 .{ }^{3}$ Isolated yield in parenthesis. ${ }^{4}$ Complete conversion of $\mathbf{1}$ into $\mathbf{3}$ was achieved after $36 \mathrm{~h}$. 
Table 3. Esterification reaction of LA 1 with 1-pentanol (2), catalyzed by A-15.

\begin{tabular}{|c|c|c|c|c|c|}
\hline Entry & Catalyst (mol \%) ${ }^{1}$ & LA/1-Pentanol & $\mathrm{T}\left({ }^{\circ} \mathrm{C}\right)$ & $t(h)$ & $C(\%)^{2}$ \\
\hline 1 & 4.3 & \multirow{9}{*}{$1: 5$} & \multirow{9}{*}{70} & 5 & 29 \\
\hline 2 & 8 & & & & 43 \\
\hline 3 & 10 & & & & 50 \\
\hline 4 & 4.3 & & & 12 & 32 \\
\hline 5 & 8 & & & & 51 \\
\hline 6 & 10 & & & & 57 \\
\hline 7 & 4.3 & & & 24 & 53 \\
\hline 8 & 8 & & & & 64 \\
\hline 9 & 10 & & & & $65(62)^{3}$ \\
\hline 10 & 4.3 & \multirow{9}{*}{$1: 5$} & \multirow{9}{*}{90} & 5 & 22 \\
\hline 11 & 8 & & & & 38 \\
\hline 12 & 10 & & & & 46 \\
\hline 13 & 4.3 & & & 12 & 33 \\
\hline 14 & 8 & & & & 39 \\
\hline 15 & 10 & & & & 52 \\
\hline 16 & 4.3 & & & 24 & 43 \\
\hline 17 & 8 & & & & 46 \\
\hline 18 & 10 & & & & 58 \\
\hline 19 & 4.3 & \multirow{9}{*}{$1: 10$} & \multirow{9}{*}{70} & 5 & 50 \\
\hline 20 & 8 & & & & 51 \\
\hline 21 & 10 & & & & 56 \\
\hline 22 & 4.3 & & & 12 & 55 \\
\hline 23 & 8 & & & & 60 \\
\hline 24 & 10 & & & & 64 \\
\hline 25 & 4.3 & & & 24 & 66 \\
\hline 26 & 8 & & & & 70 \\
\hline 27 & 10 & & & & $76(73)^{3}$ \\
\hline 28 & 4.3 & \multirow{9}{*}{$1: 10$} & \multirow{9}{*}{90} & 5 & 38 \\
\hline 29 & 8 & & & & 41 \\
\hline 30 & 10 & & & & 44 \\
\hline 31 & 4.3 & & & 12 & 50 \\
\hline 32 & 8 & & & & 52 \\
\hline 33 & 10 & & & & 54 \\
\hline 34 & 4.3 & & & 24 & 58 \\
\hline 35 & 8 & & & & 60 \\
\hline 36 & 10 & & & & 67 \\
\hline
\end{tabular}

${ }^{1}$ Referred to the amount of immobilized $-\mathrm{SO}_{3} \mathrm{H}$ moieties. ${ }^{2}$ LA conversion to pentyl levulinate 3 , determined by ${ }^{1} \mathrm{H}-\mathrm{NMR}$ analysis, using 4-bromoanisole as internal standard; the remaining material was the unreacted mixture of 1 and $2 .{ }^{3}$ Isolated yield in parenthesis.

Aquivion $\mathrm{mP} 98$ was found to be the most efficient catalyst, selectively providing up to $92 \% \mathrm{LA}$ conversion towards the target product 3 after $24 \mathrm{~h}$ at $90{ }^{\circ} \mathrm{C}$ (Table 2, entry 36). Moreover, the product was isolated in high yield $(88 \%)$ and purity $(>98 \%)$ by a simple work up procedure (see Section 3$)$. Notably, unreacted 1-pentanol could be nearly quantitatively recovered $(96 \%)$ by distillation at $75{ }^{\circ} \mathrm{C}$ under vacuum ( $80 \mathrm{mmHg}$ ) for later reuse. Additionally, complete conversion of $\mathbf{1}$ into $\mathbf{3}$ was achieved under the same optimal conditions after $36 \mathrm{~h}$. 
Table 4. Esterification reaction of LA 1 with 1-pentanol (2) catalyzed by PS-pTsOH.

\begin{tabular}{|c|c|c|c|c|c|}
\hline Entry & Catalyst (mol \%) ${ }^{1}$ & LA/1-Pentanol & $\mathrm{T}\left({ }^{\circ} \mathrm{C}\right)$ & $t(h)$ & $C(\%)^{2}$ \\
\hline 1 & 4.3 & \multirow{9}{*}{$1: 5$} & \multirow{9}{*}{70} & 5 & 32 \\
\hline 2 & 8 & & & & 44 \\
\hline 3 & 10 & & & & 58 \\
\hline 4 & 4.3 & & & 12 & 54 \\
\hline 5 & 8 & & & & 60 \\
\hline 6 & 10 & & & & 62 \\
\hline 7 & 4.3 & & & 24 & 55 \\
\hline 8 & 8 & & & & 65 \\
\hline 9 & 10 & & & & $68(64)^{3}$ \\
\hline 10 & 4.3 & \multirow{9}{*}{$1: 5$} & \multirow{9}{*}{90} & 5 & 25 \\
\hline 11 & 8 & & & & 50 \\
\hline 12 & 10 & & & & 56 \\
\hline 13 & 4.3 & & & 12 & 50 \\
\hline 14 & 8 & & & & 65 \\
\hline 15 & 10 & & & & 67 \\
\hline 16 & 4.3 & & & 24 & 50 \\
\hline 17 & 8 & & & & 69 \\
\hline 18 & 10 & & & & 68 \\
\hline 19 & 4.3 & \multirow{9}{*}{$1: 10$} & \multirow{9}{*}{70} & 5 & 43 \\
\hline 20 & 8 & & & & 50 \\
\hline 21 & 10 & & & & 56 \\
\hline 22 & 4.3 & & & 12 & 50 \\
\hline 23 & 8 & & & & 65 \\
\hline 24 & 10 & & & & 70 \\
\hline 25 & 4.3 & & & 24 & 55 \\
\hline 26 & 8 & & & & 73 \\
\hline 27 & 10 & & & & 80 \\
\hline 28 & 4.3 & \multirow{9}{*}{$1: 10$} & \multirow{9}{*}{90} & 5 & 50 \\
\hline 29 & 8 & & & & 50 \\
\hline 30 & 10 & & & & 51 \\
\hline 31 & 4.3 & & & 12 & 55 \\
\hline 32 & 8 & & & & 58 \\
\hline 33 & 10 & & & & 72 \\
\hline 34 & 4.3 & & & 24 & 60 \\
\hline 35 & 8 & & & & 65 \\
\hline 36 & 10 & & & & $83(78)^{3}$ \\
\hline
\end{tabular}

${ }^{1}$ Referred to the amount of immobilized $-\mathrm{SO}_{3} \mathrm{H}$ moieties. ${ }^{2}$ LA conversion to pentyl levulinate 3 , determined by ${ }^{1} \mathrm{H}-\mathrm{NMR}$ analysis, using 4-bromoanisole as internal standard; the remaining material was the unreacted mixture of $\mathbf{1}$ and $2 .{ }^{3}$ Isolated yield in parenthesis.

Amberlyst-15 (10 mol \%) allowed the lowest conversion at $90{ }^{\circ} \mathrm{C}$ when employing a 1:10 LA/alcohol molar ratio (Table 3, entry 36). Notably, the temperature increase led to a $\sim 10 \%$ decrease in Amberlyst-15 activity [54] (Table 3, entry 27 vs. entry 36). The effect of temperature increase on catalytic efficiency was greater for Aquivion mP98 than for PS-pTsOH (Table 2, entries 27 and 36 vs. Table 4, entries 27 and 36). Finally, Aquivion mP98 and PS-pTsOH (10 mol \%, 1:10 LA/alcohol molar ratio) allowed a higher conversion increase in the range 5-12 $\mathrm{h}$ with respect to Amberlyst- 15 , at $70{ }^{\circ} \mathrm{C}$ as well as at $90^{\circ} \mathrm{C}$. This is exemplified by Table 4, entries 30 and 33 vs. Table 2, entries 30 and 33 vs. Table 3, entries 30 and 33. The influence of the reaction temperature on the efficiency of the catalysts is also represented in Figures 1 and 2. 


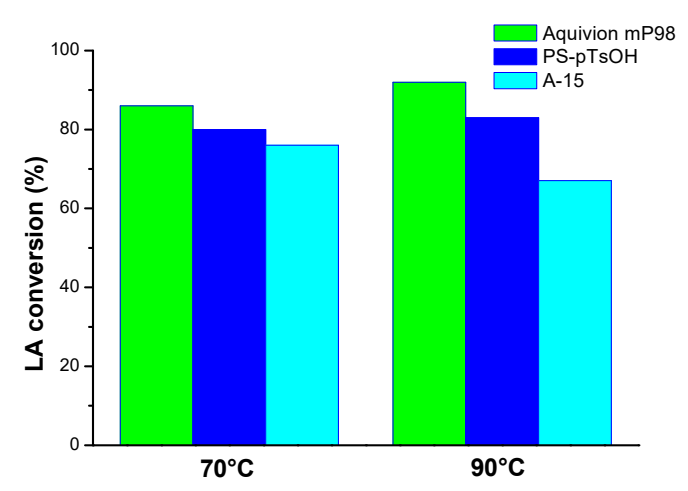

Figure 1. Effect of the temperature on the efficiency of Aquivion mP98, PS-pTsOH and A-15 (10 mol \%) in the reaction of LA with 1-pentanol (1:10 molar ratio, $24 \mathrm{~h})$.

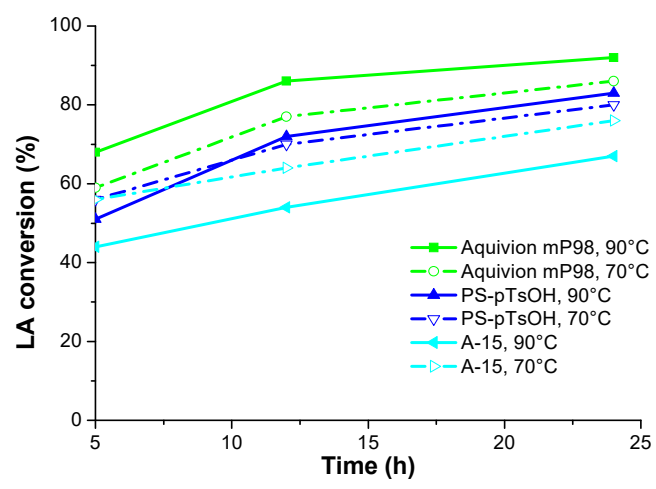

Figure 2. Effect of time and temperature on the reaction of LA with 1-pentanol (1:10 molar ratio), catalyzed by $10 \mathrm{~mol} \%$ of Aquivion mP98, PS-pTsOH and A-15.

The catalyst amount varied over a range of $4.3-10 \mathrm{~mol} \%$. Conversion of levulinic acid was found to generally increase proportionally with the catalyst amount, as the number of catalytic sites for the reaction increased. This is exemplified in Figure S2 (SM) for Aquivion mP98 $\left(1: 10\right.$ molar ratio, $\left.90^{\circ} \mathrm{C}\right)$. Also, the LA to 1-pentanol molar ratio was investigated at 1:5 and 1:10, and it was generally observed that the LA conversion into pentyl levulinate increased with an increasing molar ratio, as exemplified in Figure S3, SM.

Within each set of reaction conditions, the catalysts activity generally tracks the progression Aquivion mP98 $>$ PS-pTsOH $>$ A-15. This might be, at least partially, explained by considering the porous structure of A-15 vs. the low to non-porous structure of PS-pTsOH and Aquivion mP98, respectively. Indeed, in the case of A-15, the water produced during the esterification may limit the accessibility of reactants to the fraction of the acid sites located inside the pores, due to the fill up of the latter with water itself. Conversely, PS-pTsOH and Aquivion mP98 (nearly) hamper the adsorption of water on the outer/inner surface, which ensures the maintenance of their performance for a longer amount of time [55]. In other words, the increase in surface area, due to the presence of the pores (Table 1), seems to inhibit the esterification process under the investigated conditions. This is not uncommon behavior [55-58].

For comparison purposes, the reaction over commercially available Nafion NR50, a fluorinated congener of Aquivion mP98, has been also performed (Table S1, entry 2, SM) in optimal conditions (i.e., 1:10 LA/alcohol molar ratio, $10 \mathrm{~mol} \%$ catalyst, $90{ }^{\circ} \mathrm{C}, 24 \mathrm{~h}$ ). The lowest conversion value was achieved $(60 \%)$, and a progressive marked increase of the catalyst pellets' size was observed, which, ultimately, was responsible for a badly efficient stirring of the reaction mixture. FTIR analysis (Figure S4) of Nafion NR50 after the esterification process suggested the LA and/or pentyl levulinate adsorption on the catalytic system, although there was repeated washing. 
Furthermore, the esterification reaction over a homogeneous reference catalyst, i.e., p-toluensulfonic acid ( $\mathrm{pTsOH})$, gave a LA conversion value lower than that achieved by Aquivion mP98 under the optimal experimental conditions (Table S1, entry 3 and Table 2, entry 36, respectively). Similar results were obtained by comparing the PS-pTsOH catalyzed esterification process (Table 4, entry 36) carried out under identical conditions. On the other hand, Amberlyst 15 (Table 3, entry 36) gave lower LA conversions, thereby indicating the presence of diffusional limitations and/or catalyst instability at the temperature conditions of $90^{\circ} \mathrm{C}$ [54].

To broaden the substrate scope, a range of aliphatic alcohols $\mathbf{4 - 1 0}$ with short, moderate, and branched chains were reacted with LA using the optimized batch conditions for each catalyst to give the corresponding alkyl levulinates 11-17 (Scheme 2, Table 5).

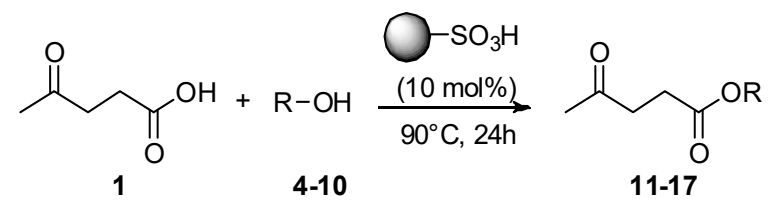

Scheme 2. Synthetic route to alkyl levulinates 11-17.

Table 5. Esterification reaction of LA with various alcohols ${ }^{1}$.

\begin{tabular}{|c|c|c|c|c|}
\hline Entry & Alcohol & Catalyst Type & $\mathrm{T}\left({ }^{\circ} \mathrm{C}\right)$ & $C(\%)^{2}$ \\
\hline 1 & & Aquivion mP98 & 90 & 58 \\
\hline 2 & & PS-p-TsOH & 90 & 58 \\
\hline 3 & & A-15 & 70 & 60 \\
\hline 4 & & Aquivion mP98 & 90 & 55 \\
\hline 5 & & PS-p-TsOH & 90 & 50 \\
\hline 6 & & A-15 & 70 & 65 \\
\hline 7 & & Aquivion mP98 & 90 & 75 \\
\hline 8 & & PS-p-TsOH & 90 & 26 \\
\hline 9 & & A-15 & 70 & 70 \\
\hline 10 & & Aquivion mP98 & 90 & 76 \\
\hline 11 & & PS-p-TsOH & 90 & 58 \\
\hline 12 & & A-15 & 70 & 58 \\
\hline 13 & & Aquivion mP98 & 90 & 84 \\
\hline 14 & & PS-p-TsOH & 90 & 62 \\
\hline 15 & & A-15 & 70 & 80 \\
\hline 16 & & Aquivion mP98 & 90 & 50 \\
\hline 17 & & PS-p-TsOH & 90 & 32 \\
\hline 18 & $\mathrm{OH}$ & A-15 & 70 & 12 \\
\hline 19 & & Aquivion mP98 & 90 & 56 \\
\hline 20 & & PS-p-TsOH & 90 & 25 \\
\hline 21 & & A-15 & 70 & 10 \\
\hline
\end{tabular}

${ }^{1}$ Reaction conditions: 1:10 LA/alcohol molar ratio, $10 \mathrm{~mol} \%$ catalyst, $90{ }^{\circ} \mathrm{C}, 24 \mathrm{~h} .{ }^{2}$ LA conversion to alkyl levulinates 11-17, determined by ${ }^{1} \mathrm{H}-\mathrm{NMR}$ analysis, using 4-bromoanisole as internal standard; the remaining material was the unreacted mixture of $\mathbf{1}$ and $\mathbf{4 - 1 0}$.

Aquivion mP98 revealed good versatility, giving a good to high conversion (50-84\%) with all of the alcohols under investigation. Notably, it was effective with branched-chain alcohols (entries 16 and 19, Table 2). This is particularly attractive since skeletally branched chain esters are considered more effective [59] as additives and diluents to improve, e.g., the cold-flow properties of biodiesel.

Additionally, no byproducts coming from the inter-/intramolecular dehydration of the different alcohols were observed under the tested reaction conditions.

The recovery and reuse of the three catalysts have been investigated, and the results reported for the reaction of LA with pentyl levulinate carried out at $70{ }^{\circ} \mathrm{C}(1: 5$ molar ratio, $10 \mathrm{~mol} \%$ catalyst, $24 \mathrm{~h})$. After the reaction was completed, the catalyst used was recovered by filtration. The recovered 
catalyst was then washed with a minimum amount of ethyl acetate, dried, and subsequently reused. All the three catalysts substantially retained their activity, even after five consecutive runs (Table S2 and Figure 3). FTIR analyses indicated that there is LA or pentyl levulinate adsorption to some extent on all resins washed, except Aquivion mP98 (Figures S4-S7, SM).

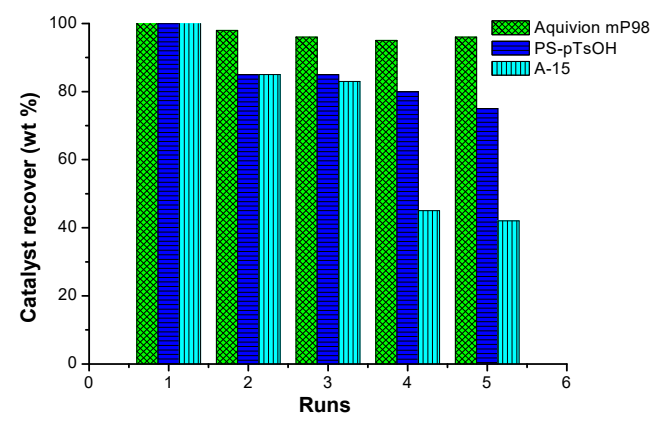

(a)

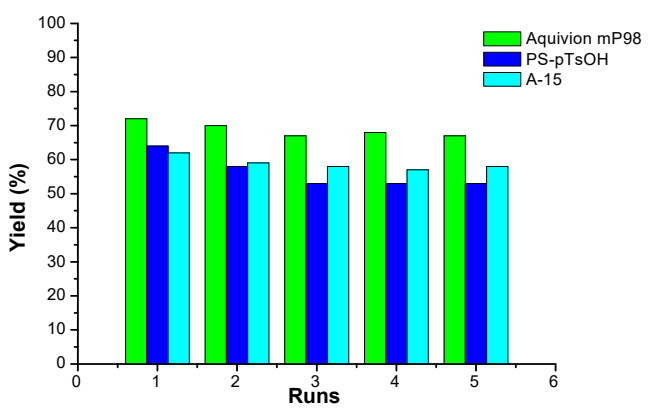

(b)

Figure 3. Recovery (a) and reuse (b) of Aquivion mP98, PS-pTsOH and A-15 in the esterification reaction of LA with 1-pentanol (1:5 molar ratio, $10 \mathrm{~mol} \%$ catalyst, $\left.70{ }^{\circ} \mathrm{C}, 24 \mathrm{~h}\right)$.

The loss of catalysts has been also evaluated. Aquivion mP98 mass was fully recovered even after five consecutive runs ( $\sim 5 \%$ weight loss), whereas PS-pTsOH was $\sim 80 \%$ recovered, and Amberlyst- 15 loss was as high as $\sim 40 \%$ (Table S2 and Figure 3). The losses were due to the mechanical disintegration of the catalyst particles, which made their recovery difficult. Indeed, the low to no-porosity of PS-pTsOH and Aquivion mP98, respectively, guaranteed their superior mechanical strength.

To confirm that there was no leaching of the catalyst $-\mathrm{SO}_{3} \mathrm{H}$ groups at the reaction temperature, a hot filtration test was carried out. Esterification of levulinic acid was therefore performed at $90{ }^{\circ} \mathrm{C}$, using the three investigated catalysts. Then, after $30 \mathrm{~min}$, the catalyst was filtered off and the reaction mixture was allowed to react further. We found that no significant further reaction occurred after this hot filtration procedure, which suggests there is no significant $-\mathrm{SO}_{3} \mathrm{H}$ leaching from the catalysts during the reaction progress (Figure S8).

To evaluate the efficiency of our synthetic strategy, we calculated the Environmental factor (E-factor, $\mathrm{kg}$ waste per $\mathrm{kg}$ product) [60]. Values in the range of $0.4-0.9$ were obtained, which includes the recovery (and reuse) of catalysts, as well as that of unreacted 1-pentanol-the optimized esterification process employing Aquivion mP98 (Table 2, entry 36) giving the minimal production of waste.

Unfortunately, it was not possible to compare the efficiency of our synthetic strategy to those of already published protocols, since essential experimental details to properly calculate the metrics are missing in these latter. As a reference, we therefore calculated the E-factor for the homogeneous p-TsOH catalyzed protocol, which showed a value of 76.36, with a consequent reduction of waste for our protocol greater than $99 \%$ (see Section 3 and SM).

To overcome the issue of the catalysts recoverability, we decided to apply the flow technology. We have therefore defined a flow protocol by charging catalysts in a PTFE or glass reactor, on the basis of the estimated volume change that follows the swelling of the polymer with the medium to be used for the process (vide supra), while the reactants' solution was charged in a tank acting as a reservoir. All the equipment was connected by using the appropriate tubes and valves, connected to a HPLC pump and installed into a thermostatic box. After setting the temperature at $90^{\circ} \mathrm{C}$, the reaction mixture was pumped through the column of appropriate length at a given flow rate (see also SM).

As shown in Table 6, entry 1, in the first run, at a flow rate of $0.1 \mathrm{~mL} / \mathrm{min}$, up to $65 \mathrm{mmol}$ of pentyl levulinate 3 over A-15 was obtained ( $93 \%$ conversion), which corresponded to a production of $0.93 \mathrm{~g}$ per hour (Turnover Number, TON: 11.5; Turnover Frequency, TOF: $0.88 \mathrm{~h}^{-1}$ ). On the other hand, much better results were obtained when using PS-p-TsOH and Aquivion mP98 (Figure S9, SM). In fact, at a 
flow rate of $0.55 \mathrm{~mL} / \mathrm{min}$, the former (Table 6, entry 3) enabled the preparation of $280 \mathrm{mmol}$ of the target product ( $98 \%$ conversion), i.e., 4.73 g per hour (TON: 47.8 , TOF: $4.3 \mathrm{~h}^{-1}$ ). Similarly, $210 \mathrm{mmol}$ of 3 were prepared over Aquivion mP98 (Table 6, entry 5) at a reaction mixture flow rate of $0.44 \mathrm{~mL} / \mathrm{min}$ ( $>99 \%$ conversion), which corresponded to $4.8 \mathrm{~g} \mathrm{~h}^{-1}$ (TON 37.4 , TOF $4.68 \mathrm{~h}^{-1}$ ).

Table 6. Reusability of catalysts in flow reactor for representative reaction to 1 -pentanol ${ }^{1}$.

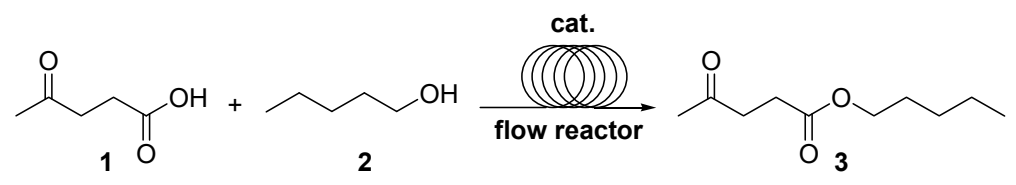

\begin{tabular}{|c|c|c|c|c|c|c|}
\hline Entry & Catalyst Type & Cycle & $C(\%)^{2}$ & $\mathrm{gxh}^{-1}$ & $\mathrm{TON}^{3}$ & TOF $\left(h^{-1}\right)^{4}$ \\
\hline 1 & \multirow[b]{2}{*}{ A-15 } & 1 & 93 & 0.93 & \multirow[b]{2}{*}{11.5} & \multirow[b]{2}{*}{0.88} \\
\hline 2 & & 2 & 93 & 0.93 & & \\
\hline 3 & \multirow{2}{*}{ PS-p-TsOH } & 1 & 98 & 4.73 & \multirow{2}{*}{47.8} & \multirow{2}{*}{4.30} \\
\hline 4 & & 2 & 98 & 4.73 & & \\
\hline 5 & \multirow{2}{*}{ Aquivion mP98 } & 1 & $>99$ & 4.8 & \multirow{2}{*}{37.4} & \multirow{2}{*}{4.68} \\
\hline 6 & & 2 & $>99$ & 4.8 & & \\
\hline
\end{tabular}

${ }^{1}$ 1:10 LA/1-pentanol molar ratio, $90{ }^{\circ} \mathrm{C} .{ }^{2}$ LA conversion to pentyl levulinate 3 , determined by ${ }^{1} \mathrm{H}-\mathrm{NMR}$ analysis, using 4-bromoanisole as internal standard; the remaining material was the unreacted mixture of $\mathbf{1}$ and $\mathbf{2} .{ }^{3}$ Turnover Number $=$ total number of moles of pentyl levulinate produced per mole of catalyst. ${ }^{4}$ Turnover frequency $=$ number of substrate molecules reacted at each available catalytic site per unit time.

The column was then dried at $120^{\circ} \mathrm{C}(3 \mathrm{~h})$ by air flow to remove the water produced during the reaction and, subsequently, a second batch of reactants was charged into the reservoir, and the activity of all resins proved to remain unchanged (Table 6, entries 2, 4, 6, and SM).

\section{Materials and Methods}

\subsection{General Remarks}

All reagents were purchased from commercial sources and used without further purification, unless otherwise noted. Commercial Amberlyst- $15^{\circledR}\left(4.7 \mathrm{mmol} \mathrm{SO}{ }_{3} \mathrm{H} / \mathrm{g}\right.$, particle size $\left.<0.3 \mathrm{~mm}\right)$, polystyrene-bound p-toluensulfonic acid ( $\mathrm{PS}-\mathrm{pTsOH} ; 2.9 \mathrm{mmol} \mathrm{SO}_{3} \mathrm{H} / \mathrm{g}$, particle size: $0.25-0.59 \mathrm{~mm}$ ), and Nafion ${ }^{\circledR} \mathrm{NR} 50\left(0.8 \mathrm{mmol} \mathrm{SO}{ }_{3} \mathrm{H} / \mathrm{g}\right.$, particle size $\left.\sim 3.5 \mathrm{~mm}\right)$ were purchased at Sigma-Aldrich, $\mathrm{Si}$ Milan, Italy. Aquivion mP98 $(1.2 \mathrm{mmol} \mathrm{SO} 3 \mathrm{H} / \mathrm{g}$, particle size $\sim 0.7 \mathrm{~mm})$ was provided by Solvay Specialty Polymers S.p.A. Elemental microanalyses were performed using a Fison's EA1106CHN analyzer using atropine, 2,5-bis-2-(5-tertbutylbenzoxazol-yl)-thiophene (BBOT), and phenanthrene as a reference standard, with an accuracy of ca. $2 \mu \mathrm{mol} \mathrm{g}{ }^{-1}$. NMR spectra were recorded on a Bruker DRX-ADVANCE $400 \mathrm{MHz}\left({ }^{1} \mathrm{H}\right.$ at $400 \mathrm{MHz}$ and ${ }^{13} \mathrm{C}$ at $\left.100.6 \mathrm{MHz}\right)$ in $\mathrm{CDCl}_{3}$, using TMS as an internal standard. Fourier Transformed Infrared (FTIR) spectra were recorded on a VERTEX 70 Bruker Optics Instrument (Billerica, MA, USA), with a spectral range of $4000-400 \mathrm{~cm}^{-1}$ and a resolution of $4 \mathrm{~cm}^{-1}$, equipped with a single reflection diamond ATR cell.

\subsection{Representative Experimental Batch Procedure for the Preparation of Pentyllevulinate 3 over Heterogeneous Acid Catalysts}

In a round-bottomed flask capped with a PTFE stopper and equipped with a magnetic stirrer, levulinic acid $(1 \mathrm{~g}, 8.6 \mathrm{mmol}), 1$-pentanol $(9.35 \mathrm{~mL}, 86 \mathrm{mmol})$ and Aquivion $\mathrm{mP9} 9$ catalyst $\left(10 \mathrm{~mol} \% 0.7 \mathrm{~g}\right.$ ) were consecutively added. The mixture was left under stirring at $90{ }^{\circ} \mathrm{C}$ for $24 \mathrm{~h}$. Then the reaction mixture was cooled down to room temperature and the catalyst filtered off and washed with ethyl acetate $(80 \mathrm{~mL})$. The filtrate was concentrated by removing solvent and unreacted 1-pentanol was recovered $(96 \%)$ by distillation at $75{ }^{\circ} \mathrm{C}$ under vacuum $(80 \mathrm{mmHg})$. Subsequent filtration using a basic $\mathrm{Al}_{2} \mathrm{O}_{3}$ pad $(0.15 \mathrm{~g})$ to remove the residual LA gave pentyl levulinate 3 as a pale yellow oil $(1.43 \mathrm{~g}$, 
$7.57 \mathrm{mmol}, 88 \%$ yield). ${ }^{1} \mathrm{H}-\mathrm{NMR} \delta(\mathrm{ppm}) 3.9(\mathrm{t}, 2 \mathrm{H}) ; 2.6(\mathrm{~m}, 2 \mathrm{H}) ; 2.4(\mathrm{~m}, 2 \mathrm{H}) ; 2.1(\mathrm{~s}, 3 \mathrm{H}) ; 1.5(\mathrm{~m}, 2 \mathrm{H}) ; 1.2$ $(\mathrm{m}, 4 \mathrm{H}) ; 0.81(\mathrm{~m}, 3 \mathrm{H})$. E-factor: [1 g (LA) $+7.6 \mathrm{~g}$ (1-pentanol) + $0.2 \mathrm{~g}(\mathrm{Al} 2 \mathrm{O} 3)-1.63 \mathrm{~g}$ (pentyl levulinate 3) $-6.5 \mathrm{~g}(96 \%$ recovered 1-pentanol) $] / 1.63 \mathrm{~g}$ (pentyl levulinate 3$)=0.4$.

The Aquivion mP98 catalyst was not considered in the calculation due to its complete recovery.

\subsection{Esterification Reaction to Pentyllevulinate 3 over Homogeneous p-TsOH Catalyst}

In a round-bottomed flask capped with a PTFE stopper and equipped with a magnetic stirrer, levulinic acid $(0.8 \mathrm{~g}, 6.8 \mathrm{mmol}), 1$-pentanol $(7.37 \mathrm{~mL}, 68 \mathrm{mmol})$ and p-toluen sulfonic acid (pTsOH, $10 \mathrm{~mol} \%, 0.12 \mathrm{~g}$ ) were consecutively added. The mixture was left under stirring at $90{ }^{\circ} \mathrm{C}$ for $24 \mathrm{~h}$. Then, the reaction mixture was cooled down to room temperature, diluted with ethyl acetate $(10 \mathrm{~mL})$, washed with $\mathrm{NaHCO}_{3}$ saturated solution $(20 \mathrm{~mL} \times 3)$, dried over $\mathrm{Na}_{2} \mathrm{SO}_{4}$, filtered, and concentrated to remove solvent. Next, $90 \%$ of unreacted 1-pentanol was recovered by distillation at $75{ }^{\circ} \mathrm{C}$ under vacuum ( $80 \mathrm{mmHg})$. Pentyl levulinate 3 was obtained as a pale yellow oil $(0.98 \mathrm{~g}, 5.3 \mathrm{mmol}, 78 \%$ yield). E-factor: $0.8 \mathrm{~g}(\mathrm{LA})+0.12 \mathrm{~g}(\mathrm{pTsOH})+6 \mathrm{~g}(1-$ pentanol $)+8.9 \mathrm{~g}$ (ethyl acetate) $+5.4 \mathrm{~g}\left(\mathrm{NaHCO}_{3}\right)+60 \mathrm{~g} \mathrm{H}_{2} \mathrm{O}-0.98$ $\mathrm{g}$ (pentyllevulinate 3$)-5.4 \mathrm{~g}(90 \%$ recovered 1-pentanol $) / 0.98 \mathrm{~g}($ pentyl levulinate 3$)=76.37$.

This doesn't account for the drying agent.

\section{Conclusions}

Three members of the acidic resins family featuring different morphologies, namely non-porous micronized Aquivion ${ }^{\circledR}$ PFSA (Aquivion mP98), macroreticular Amberlyst- $15^{\circledR}$, and macroporous polystyrene-supported p-toluensulfonic acid (PS-pTsOH), were active catalysts in the esterification reaction of levulinic acid with 1-pentanol, both under conventional batch conditions and in flow. The activity generally tracked the progression Aquivion mP98 > PS-pTsOH > A-15, which was tentatively explained on the basis of the different porous structure of the catalytic systems. Particularly, non-porous Aquivion mP98 (10 mol \%) allowed the highest levulinic acid conversion (92\%) into pentyl levulinate under conventional batch conditions at $90^{\circ} \mathrm{C}$ when employing a 1:10 LA/alcohol molar ratio $(24 \mathrm{~h})$. Moreover, the reaction was completely selective and the product was isolated ( $88 \%$ yield) by a straightforward procedure, encompassing the almost complete recovery $(96 \%)$ of unreacted 1-pentanol by distillation, for later reuse. The protocol could be extended to aliphatic alcohols with short, moderate, and branched chains, leading to the preparation of levulinates in good-to-high yields (50-92\%). Moreover, no byproducts coming from inter-/intramolecular dehydration of the different alcohols were observed under the tested reaction conditions.

Recovery and reuse of all the three catalysts have been investigated. Notably, non-porous Aquivion mP98 substantially retained its activity even after five consecutive runs, while being fully recoverable ( $\sim 5 \%$ weight loss).

Calculation of the E-factors confirmed that our approach is very efficient for waste reduction, especially in the case of the flow conditions (E-factor as low as ca. 0.3). Importantly, the flow technique proved to be an efficient solution to maintain the physical integrity of the catalysts and also to allow for its easy recovery and recycling. Additionally, flow conditions enabled the production of levulinates on a g per hour scale when employing the low- to non-porous catalysts PS-pTsOH and Aquivion mP98, respectively.

Further investigations are due in due course to demonstrate that resin-supported acid catalysts can improve substantially the overall efficiency of valuable fuel esters production.

Supplementary Materials: The following are available online at www.mdpi.com/2073-4344/7/8/235/s1, E-factor calculation, Table S1: Esterification reaction of LA with 1-pentanol in batch conditions, Table S2: Recycling of Aquivion mP98, PS-pTsOH and Amberlyst-15 in esterification reaction of LA with 1-pentanol, Figure S1: Swelling in 1-pentanol of the three investigated resins, Figure S2: Effect of Aquivion mP98 catalyst loading on conversion of levulinic acid into pentyl levulinate (1:10 LA to pentanol molar ratio, $\left.90{ }^{\circ} \mathrm{C}\right)$, Figure S3: Effect of the mole ratio on conversion of levulinic acid into pentyl levulinate $(10 \mathrm{~mol} \%$ catalyst, $24 \mathrm{~h})$, Figure S4: FTIR spectra of Nafion NR50 before use and after esterification reaction of LA with 1-pentanol, Figure S5: FTIR spectra of Aquivion mP98 before use and after five runs, Figure S6: FTIR spectra of PS-pTsOH before use and after five 
runs, Figure S7: FTIR spectra of Amberlyst 15 before use and after five runs, Figure S8: Hot filtration test for the heterogeneous acid catalyzed esterification reaction of LA and 1-pentanol (1:5 molar ratio, $10 \mathrm{~mol} \%$ catalyst) at $90{ }^{\circ} \mathrm{C}$, Figure S9: Comparison between the abilities of the investigated catalysts in producing pentyl levulinate 3 under flow conditions.

Acknowledgments: This research has been developed and partially financed within the National project "BIT3G"-Italian Green Chemistry Cluster. We gratefully acknowledge Maria Paola Bracciale (University of Rome "Sapienza") for FTIR analyses.

Author Contributions: V.T., L.B., A.Z., A.P., M.C. performed the experiments and analyzed the data; O.P. contributed reagents/materials/analysis tools; A.M. and L.V. conceived and designed the experiments and wrote the paper. www.dcbb.unipg.it/greensoc.

Conflicts of Interest: The authors declare no conflict of interest. The founding sponsors had no role in the design of the study; in the collection, analyses, or interpretation of data and in the writing of the manuscript.

\section{References}

1. Bozell, J.J.; Moens, L.; Wang, D.C.; Fitzpatrick, G.G.; Bilsky, S.W.; Jarnefeld, R.J. Production of levulinic acid and use as a platform chemical for derived products. Resour. Conserv. Recycl. 2000, 28, 227-239. [CrossRef]

2. Bozell, J.J.; Petersen, G.R. Technology development for the production of biobased products from biorefinery carbohydrates-The U.S. Department of Energy's “Top 10" revisited. Green Chem. 2010, 12, 539-554. [CrossRef]

3. Werpy, T.A.; White, J.E. (Eds.) Top Value Added Chemicals from Biomass. I. Results of Screening for Potential Candidates from Sugars and Synthesis Gas. U.S. DOE-NREL Report. Available online: https:/ / www.nrel.gov / docs/fy04osti/35523.pdf (accessed on August 2004).

4. Climenten, M.J.; Corma, A.; Iborra, S. Conversion of biomass platform molecules into fuel additives and liquid hydrocarbon fuels. Green Chem. 2014, 16, 516-547. [CrossRef]

5. Yan, K.; Jarvis, C.; Gu, J.; Yan, Y. Production and catalytic transformation of levulinic acid: A platform for speciality chemicals and fuels. Renew. Sustain. Energy Rev. 2015, 51, 986-997. [CrossRef]

6. Palkovits, R. Pentenoic acid pathways for cellulosic biofuels. Angew. Chem. Int. Ed. 2010, 49, 4336-4338. [CrossRef] [PubMed]

7. Paul, S.F. Alternative Fuel. U.S. Patent 20016309430, 30 October 2001.

8. Zheng, J.; Zhu, J.; Xu, X.; Wang, W.; Li, J.; Zhao, Y.; Tang, K.; Song, Q.; Kong, D.; Tamg, Y. Continuous hydrogenation of ethyl levulinate to $\gamma$-valerolactone and 2-methyl tetrahydrofuran over alumina doped $\mathrm{Cu} / \mathrm{SiO}_{2}$ catalyst: The potential of commercialization. Sci. Rep. 2016, 6, 28898. [CrossRef] [PubMed]

9. Bond, J.Q.; Alonso, D.M.; Wang, D.; West, R.M.; Dumesic, J.A. Integrated catalytic conversion of gamma-valerolactone to liquid alkenes for transportation fuels. Science 2010, 327, 1110-1114. [CrossRef] [PubMed]

10. Lange, J.P.; Price, R.; Ayoub, P.M.; Jurgen, L.; Petrus, L.; Clarke, L. Valeric biofuels: A platform of cellulosic transportation fuels. Angew. Chem. Int. Ed. 2010, 49, 4479-4483. [CrossRef] [PubMed]

11. Serrano-Ruiz, J.C.; Braden, D.J.; West, R.M.; Dumesic, J.A. Conversion of cellulose to hydrocarbon fuels by progressive removal of oxygen. Appl. Catal. B Environ. 2010, 100, 184-189. [CrossRef]

12. Christensen, E.; Yanovitz, J.; Ratcliff, M.; McCormick, R. Renewable Oxygenate Blending Effects on Gasoline Properties. Energy Fuels 2011, 25, 5422-5428. [CrossRef]

13. Fanick, A.; Cahana, A. Novel Renewable Additive for Diesel Engines; SAE Technical Paper 2014-01-1262; SAE International: Warrendale, PA, USA, 2014.

14. Groves, A.; Morley, C.; Smith, J.; Stevenson, P.A. Fuel Compositions. U.S. Patent 20050144835 A1, 7 July 2005.

15. Lake, M.A.; Burton, S.W. Diesel Fuel Compositions Containing Levulinate Ester. U.S. Patent 20100313467 A1, 16 December 2010.

16. Shrivastav, G.; Khan, T.S.; Agarwal, M.; Haider, M.A. Reformulation of Gasoline to Replace Aromatics by Biomass-Derived Alkyl Levulinates. ACS Sustain. Chem. Eng. 2017, 5, 7118-7127. [CrossRef]

17. Texaco. Ethyl Levulinate D-975 Diesel Additive Test Program; Texaco/NYSERDA/Biofine Inc.: Glenham, NY, USA, 2000.

18. Jannsen, A.; Muether, M.; Kolbeck, A.; Lamping, M.; Pischinger, S. The Impact of Different Biofuel Components in Diesel Blends on Engine Efficiency and Emission Performance; SAE Technical Paper 2010-01-2119; SAE International: Warrendale, PA, USA, 2010. 
19. Wang, Z.; Lei, T.; Liu, L.; Zhu, J.; He, X.; Li, Z. Performance Investigations of a Diesel Engine Using Ethyl Levulinate-Diesel Blends. BioResources 2012, 7, 5972-5982. [CrossRef]

20. Wang, Z.; Chan, X.; Lin, L.; Jan, X.; San, Y.; Shi, X.; He, X.; Zhu, J. Performance and emission characteristics of a diesel engine running on optimized ethyl levulinate-biodiesel-diesel blends. Energy 2016, 95, $29-40$. [CrossRef]

21. Jenkins, R.W.; Munro, M.; Nash, S.; Chuck, C.J. Potential renewable oxygenated biofuels for the aviation and road transport sectors. Fuel 2013, 103, 593-599. [CrossRef]

22. Dèmolis, A.; Essayem, N.; Rataboul, F. Synthesis and Applications of Alkyl Levulinates. ACS Sustain. Chem. Eng. 2014, 2, 1338-1352. [CrossRef]

23. Luque, R.; Herrero-Davila, L.; Campelo, J.M.; Clark, J.H.; Hidalgo, J.M.; Luna, D.; Marinas, J.M.; Romero, A.A. Biofuels: A technological perspective. Energy Environ. Sci. 2008, 1, 542-564. [CrossRef]

24. Nandiwale, K.Y.; Sonar, S.K.; Niphadkar, P.S.; Joshi, P.N.; Deshpande, S.S.; Patil, V.S.; Bokade, V.V. Catalytic upgrading of renewable levulinic acid to ethyl levulinate biodiesel using dodecatungstophosphoric acid supported on desilicated H-ZSM-5 as catalyst. Appl. Catal. A 2013, 460-461, 90-98. [CrossRef]

25. Pasquale, G.; Vasquez, P.; Romanelli, G.; Baronetti, G. Catalytic upgrading of levulinic acid to ethyl levulinate using reusable silica-included Wells-Dawson heteropolyacid as catalyst. Catal. Commun. 2012, 18, 115-120. [CrossRef]

26. Yan, K.; Wu, G.; Wen, J. One-step synthesis of mesoporous $\mathrm{H}_{4} \mathrm{SiW}_{12} \mathrm{O}_{40}-\mathrm{SiO}_{2}$ catalysts for the production of methyl and ethyl levulinate biodiesel. Catal. Commun. 2013, 34, 58-63. [CrossRef]

27. Nandiwale, K.Y.; Bokade, V.V. Environmentally benign catalytic process for esterification of renewable levulinic acid to various alkyl levulinates biodiesel. Environ. Prog. Sustain. Energy 2015, 34, 795-801. [CrossRef]

28. Patil, C.R.; Niphadkar, P.S.; Bokade, V.V.; Joshi, P.N. Esterification of levulinic acid to ethyl levulinate over bimodal micro-mesoporous H/BEA zeolite derivatives. Catal. Commun. 2014, 43, 188-191. [CrossRef]

29. An, S.; Song, D.; Lu, B.; Yang, X.; Guo, Y.H. Morphology Tailoring of Sulfonic Acid Functionalized Organosilica Nanohybrids for the Synthesis of Biomass-Derived Alkyl Levulinates. Chem. Eur. J. 2015, 21, 10786-10798. [CrossRef] [PubMed]

30. Su, F.; Ma, L.; Guo, X.H.; Li, W. Preparation of ethane-bridged organosilica group and keggin type heteropoly acid co-functionalized $\mathrm{ZrO}_{2}$ hybrid catalyst for biodiesel synthesis from eruca sativa gars oil. Catal. Sci. Technol. 2012, 2, 2367-2374. [CrossRef]

31. Su, F.; Ma, L.; Song, D.; Zhang, X.; Guo, Y. Design of a highly ordered mesoporous $\mathrm{H}_{3} \mathrm{PW}_{12} \mathrm{O}_{40} / \mathrm{ZrO}{ }_{2}-\mathrm{Si}(\mathrm{Ph}) \mathrm{Si}$ hybrid catalyst for methyl levulinate synthesis. Green Chem. 2013, 15, 885-890. [CrossRef]

32. Su, F.; Wu, Q.; Song, D.; Zhang, X.; Wang, M.; Guo, Y. Pore morphology-controlled preparation of $\mathrm{ZrO}_{2}$-based hybrid catalysts functionalized by both organosilica moieties and Keggin-type heteropoly acid for the synthesis of levulinate esters. J. Mater. Chem. A 2013, 1, 13209-13221. [CrossRef]

33. Budarin, V.L.; Clark, J.H.; Luque, R.; Macquarrie, D.J. Versatile mesoporous carbonaceous materials for acid catalysis. Chem. Commun. 2007, 6, 634-636. [CrossRef] [PubMed]

34. Lam, E.; Luong, J.H.T. Carbon Materials as Catalyst Supports and Catalysts in the Transformation of Biomass to Fuels and Chemicals. ACS Catal. 2014, 4, 3393-34910. [CrossRef]

35. Nakate, A.V.; Yadav, G.D. Synthesis and Characterization of Sulfonated Carbon-Based Graphene Oxide Monolith by Solvothermal Carbonization for Esterification and Unsymmetrical Ether Formation. ACS Sustain. Chem. Eng. 2016, 4, 1963-1973. [CrossRef]

36. Oliveira, B.L.; da Silva, V.T. Sulfonated carbon nanotubes as catalysts for the conversion of levulinic acid into ethyl levulinate. Catal. Today 2014, 234, 257-263. [CrossRef]

37. Li, Z.; Wnetrzak, R.; Kwapinski, W.; Leahy, J.J. Synthesis and Characterization of Sulfated $\mathrm{TiO}_{2} \mathrm{Nanorods}$ and $\mathrm{ZrO}_{2} / \mathrm{TiO}_{2}$ Nanocomposites for the Esterification of Biobased Organic Acid. ACS Appl. Mater. Interfaces 2012, 4, 4499-4505. [CrossRef] [PubMed]

38. Yadav, G.D.; Yadav, A.R. Synthesis of ethyl levulinate as fuel additives using heterogeneous solid superacidic catalysts: Efficacy and kinetic modeling. Chem. Eng. J. 2014, 243, 556-563. [CrossRef]

39. Kuwahara, Y.; Karubagi, W.; Nemoto, K.; Fujitani, T. Esterification of levulinic acid with ethanol over sulfated Si-doped $\mathrm{ZrO}_{2}$ solid acid catalyst: Study of the structure-activity relationships. Appl. Catal. A 2014, 476, 186-196. [CrossRef] 
40. Fernandes, D.R.; Rocha, A.S.; Mai, E.F.; Mota, C.J.A.; Teixeira da Silva, V. Levulinic acid esterification with ethanol to ethyl levulinate production over solid acid catalysts. Appl. Catal. A 2012, 425, 199-204. [CrossRef]

41. Maggi, R.; Shijiu, N.R.; Santacroce, V.; Maestri, G.; Bigi, F.; Rothenberg, G. Silica-supported sulfonic acids as recyclable catalyst for esterification of levulinic acid with stoichiometric amounts of alcohols. Beilstein J. Org. Chem. 2016, 12, 2173-2180. [CrossRef] [PubMed]

42. Melero, J.A.; Morales, G.; Iglesias, J.; Paniagua, M.; Hernandez, B.; Penedo, S. Efficient conversion of levulinic acid into alkyl levulinates catalyzed by sulfonic mesostructured silicas. Appl. Catal. A 2013, 466, 116-122. [CrossRef]

43. Barbaro, P.; Liguori, F. Ion Exchange Resins: Catalyst Recovery and Recycle. Chem. Rev. 2009, 109, 515-529. [CrossRef] [PubMed]

44. Chang, Y.; Bae, C. Polymer-Supported Acid Catalysis in Organic Synthesis. Curr. Org. Chem. 2011, 8, $208-236$. [CrossRef]

45. Gelbard, G. Organic Synthesis by Catalysis with Ion-Exchange Resins. Ind. Eng. Chem. Res. 2005, 44, 8468-8498. [CrossRef]

46. Mallesham, B.; Rao, B.G.; Reddy, B.M. Production of biofuel additives by esterification and acetalization of bioglycerol. C. R. Chim. 2016, 19, 1194-1202. [CrossRef]

47. Tejero, M.A.; Ramìrez, E.; Fitè, C.; Tejero, J.; Cunill, F. Esterification of levulinic acid with butanol over ion exchange resins. Appl. Catal. A 2016, 517, 55-56. [CrossRef]

48. Vaccaro, L.; Lanari, D.; Marrocchi, A.; Strappaveccia, G. Flow approches towards sustainability. Green Chem. 2014, 16, 3680-3704. [CrossRef]

49. Marrocchi, A.; Adriaensens, P.; Bartollini, E.; Barkakati, B.; Carleer, R.; Chen, J.; Hensley, D.K.; Petrucci, C.; Tassi, M.; Vaccaro, L. Novel cross-linked polystyrenes with large space network as tailor-made catalyst supports for sustainable media. Eur. Pol. J. 2015, 75, 391-401. [CrossRef]

50. Castrica, L.; Fringuelli, F.; Gregoli, L.; Pizzo, F.; Vaccaro, L. Amberlite IRA900N3 as a new catalyst for the azidation of alpha,beta-unsaturated ketones under solvent-free conditions. J. Org. Chem. 2006, 71, 9536-9539. [CrossRef] [PubMed]

51. Fringuelli, F.; Pizzo, F.; Vaccaro, L. First Efficient Regio- and Stereoselective Metal-Catalyzed Azidolysis of 2,3-Epoxycarboxylic Acids in Water. Synlett 2000, 311-314. [CrossRef]

52. Luis, S.V.; Garcia-Verdugo, E. (Eds.) Chemical Reactions and Processes under Flow Conditions; Royal Society of Chemistry: Cambridge, UK, 2010.

53. Chernysheva, L.; Comino, G.; Brinati, G. Milling Process. Patent WO 2013023983 A1, 21 February 2013.

54. Margolese, D.; Melero, J.A.; Christiansen, S.C.; Chmelka, B.F.; Stucky, J.D. Direct Syntheses of Ordered SBA-15 Mesoporous Silica Containing Sulfonic Acid Groups. Chem. Mater. 2000, 12, 2448-2459. [CrossRef]

55. Park, J.Y.; Kim, D.K.; Lee, J.S. Esterification of free fatty acids using water-tolerable Amberlyst as a heterogeneous catalyst. Bioresour. Technol. 2010, 101, S62-S65. [CrossRef] [PubMed]

56. Park, J.Y.; Wang, Z.M.; Kim, D.K.; Lee, J.S. Effects of water on the esterification of free fatty acids by acid catalysts. Renew. Energy 2010, 35, 614-618. [CrossRef]

57. Russbueldt, B.M.E.; Hoelderich, W.F. New sulfonic acid ion-exchange resins for the preesterification of different oils and fats with high content of free fatty acids. Appl. Catal. A Gen. 2009, 362, 47-57. [CrossRef]

58. Kouzu, M.; Nakagaito, A.; Hidaka, J.-S. Pre-esterification of FFA in plant oil transesterified into biodoesel with the help of solid acid catalysis of sulfonated cation-exchange resin. Appl. Catal. A Gen. 2011, 405, 36-44. [CrossRef]

59. Knothe, G. Dependence of biodiesel fuel properties on the structure of fatty acid alkyl esters. Fuel Proc. Technol. 2005, 86, 1059-1070. [CrossRef]

60. Sheldon, R.A. E factors, green chemistry and catalysis: An odyssey. Chem. Commun. 2008, 29, 3352-3365. [CrossRef] [PubMed]

(C) 2017 by the authors. Licensee MDPI, Basel, Switzerland. This article is an open access article distributed under the terms and conditions of the Creative Commons Attribution (CC BY) license (http:/ / creativecommons.org/licenses/by/4.0/). 